\title{
Reducing Propulsion Airframe Aeroacoustic Interactions with Uniquely Tailored Chevrons: 3. Jet-Flap Interaction
}

\author{
Vinod G. Mengle ${ }^{*}$, Leon Brusniak ${ }^{\dagger}$, Ronen Elkoby ${ }^{\ddagger}$ \\ The Boeing Company, Seattle, WA 98124-2207 \\ and \\ Russ H. Thomas ${ }^{\S}$ \\ NASA Langley Research Center, Hampton, VA, 23681-2199
}

\begin{abstract}
Propulsion airframe aeroacoustic (PAA) interactions, resulting from the integration of engine and airframe, lead to azimuthal asymmetries in the flow/acoustic field, e.g., due to the interaction between the exhaust jet flow and the pylon, the wing and its high-lift devices, such as, flaps and flaperons. In the first two parts of this series we have presented experimental results which show that isolated and installed nozzles with azimuthally varying chevrons (AVCs) can reduce noise more than conventional chevrons when integrated with a pylon and a wing with flaps at take-off conditions. In this paper, we present model-scale experimental results for the reduction of jet-flap interaction noise source due to these AVCs and document the PAA installation effects (difference in noise between installed and isolated nozzle configurations) at both approach and take-off conditions. It is found that the installation effects of both types of chevron nozzles, AVCs and conventional, are reversed at approach and take-off, in that there is more installed noise reduction at approach and less at take-off compared to that of the isolated nozzles. Moreover, certain AVCs give larger total installed noise benefits at both conditions compared to conventional chevrons. Phased microphone array results show that at approach conditions (large flap deflection, low jet speed and low ambient Mach number), chevrons gain more noise benefit from reducing jetflap interaction noise than they do from quieting the jet plume noise source which is already weak at these low jet speeds. In contrast, at take-off (small flap deflection, high jet speed and high ambient Mach number) chevrons reduce the dominant jet plume noise better than the reduction they create in jet-flap interaction noise source. In addition, fan AVCs with enhanced mixing near the pylon are found to reduce jet-flap interaction noise better than conventional chevrons at take-off.
\end{abstract}

\section{Nomenclature}

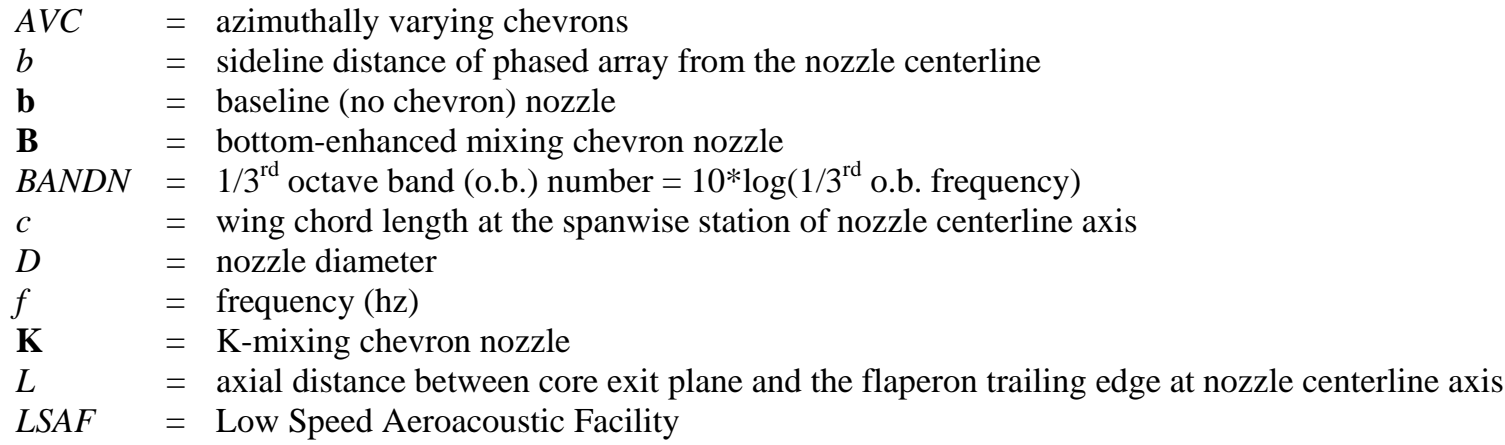

\footnotetext{
* Engineer/Scientist, Acoustics \& Fluid Mechanics Dept., P.O. Box 3707, MC: 67-ML, Sr. Member, AIAA.

${ }^{\dagger}$ Engineer/Scientist, Acoustics \& Fluid Mechanics Dept., P.O. Box 3707, MC: 67-ML.

${ }^{\ddagger}$ Engineer/Scientist, 787 Product Development Group, P.O. Box 3707, MC: OR-MM, Member, AIAA.

$\S$ Senior Research Engineer, Aeroacoustics Branch, MS 166, Sr. Member, AIAA.
} 


$\begin{array}{lrl}M_{w t} & = & \text { wind-tunnel Mach number } \\ N P R_{c}, N P R_{f} & =\text { nozzle pressure ratio of core (or primary) and fan (or secondary) stream, respectively } \\ O A S P L & = & \text { overall sound pressure level (dB) } \\ P A A & = & \text { propulsion airframe aeroacoustics } \\ R & = & \text { radial distance of polar array of microphones from the core nozzle exit center } \\ S P L & = & \text { sound pressure level }(\mathrm{dB}) \\ T T R & = & \text { ratio of total temperature of primary and secondary streams } \\ \mathbf{T} & = & \text { top-enhanced mixing chevron nozzle } \\ \mathbf{V} & = & \text { variable immersion chevron nozzle with K-type mixing } \\ \theta & = & \text { microphone angle }\end{array}$

\section{Introduction}

W HEN an engine is placed in the vicinity of an airplane the flow/acoustic interactions between them change considerably. Such interactions due to engine installation are called Propulsion Airframe Aeroacoustic (PAA) interactions, and PAA is becoming an important and fast-growing area in aeroacoustics research. The change in the flow/acoustic field can arise, for example, due to the pylon or strut used in the installation, the reflection and diffraction of engine noise by the wing and its high-lift devices, like, flaps, or the interaction of the exhaust jet and flaps which can generate new noise sources, like, jet-flap interaction noise. Our focus here is on the reduction of overall airplane noise due to the jet and its interaction with the pylon and the wings. With more and more stringent community noise regulations on airplane noise at the airports, we need to seek better and better ways to reduce it, and studying different and novel ways to reduce PAA interactions can help this goal incrementally.

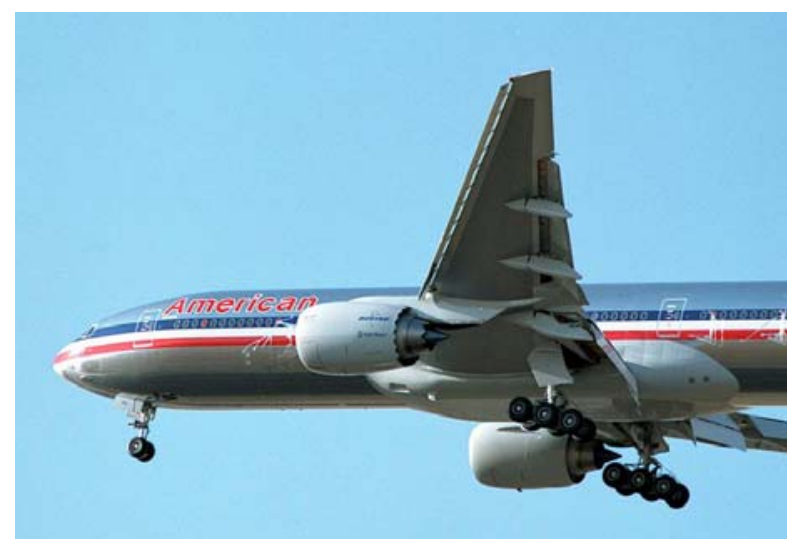

Figure 1. Deflected flaps/flaperons are typically in the jet exhaust plume or in the flow entrained by the jet during approach condition creating jet-flap interaction noise.

When engines are installed on an airplane, say, underneath the wing, as is typical in modern jet airplanes, there exists an inherent top-bottom asymmetry in the flow/acoustic environment. For example, the pylon is only on the top side of the jet, the wing reflects engine noise from the upper side to an observer below it and the jet-flap interaction is also from one side, the top one. Figure 1 shows such a plane in approach condition with the flaps deflected. However, conventional chevrons which have been used to reduce jet noise ${ }^{1,2}$ have not taken advantage of this top-bottom asymmetry to reduce jet-related noise any further. In Part $1^{3}$ of this trio of papers ${ }^{4}$, we introduced the concept of azimuthally varying chevrons (AVC) to take advantage of this asymmetry and systematically analyzed results when such AVCs are used in "isolated" nozzles, inclusive of a pylon. In Part $2^{4}$, we extended this study to "installed" nozzles with a fuselage and wing with high lift devices, such as, flaps, flaperon and leading-edge slats. This paper, which is Part 3 of this series, is a continuation of this work to examine the effects of AVCs on PAA when the nozzles are installed under the wing and compare them with the results for isolated nozzles, in particular, focusing on the changes in jet-flap interaction (JFI) noise sources. General work on JFI noise can be found, for example, in Fink $^{5}$ and Crighton ${ }^{6}$.

This work is part of a larger Boeing and NASA PAA-related collaboration under the Quiet Technology Demonstrator 2 (QTD2) program whose overview is given in Herkes et $\mathrm{al}^{7}$. Most of the relevant references on PAA work with and without chevrons, and the AVC concept can be found in Parts 1 and 2 (from this point on we will simply refer to Ref. 3 as Part 1 and Ref. 4 as Part 2) and will not be repeated here; the reader is urged to read this paper in conjunction with Parts 1 and 2 for a more complete understanding.

Briefly, in Part 1, we introduced, designed and tested scale models of different types of azimuthally varying chevrons, like, the top- or the bottom-enhanced mixing chevrons which, as the names imply, are supposed to enhance the mixing between the two streams around the chevrons at the top near the pylon or at the bottom, away from the pylon. Conventional chevrons, it may be recalled, are azimuthally uniform, that is, do not vary in shape or size from chevron to chevron. These tests were conducted in Boeing's Low Speed Aeroacoustics Facility (LSAF) with a free jet. In Parts 1 and 2, we discovered that certain types of AVCs, like the top-enhanced mixing fan 
chevrons, were quieter than the conventional state-of-the-art chevrons when tested as isolated nozzles with a pylon or when installed under a wing with high-lift devices. Importantly, this occurred without any appreciable highfrequency lift, which is otherwise endemic to the conventional chevrons and reduce their perceived noise benefits due to higher noy weighting at higher frequencies. However, as seen in Part 2, the installed noise benefits for all these chevron nozzles were lower than their isolated noise benefits at take-off conditions. That is, installation under the wing suppressed their noise benefits found in isolated nozzle configurations with a pylon, at least at take-off conditions studied. This aspect is important from a practical viewpoint and will be further studied here.

In the isolated nozzle configuration for AVCs (Part 1), we also captured the better reduction of noise source in the exhaust jet plume compared not only to the baseline nozzle but also the conventional chevron nozzle. In the installed nozzle case for AVCs (Part 2) we studied the installation effects and installed noise benefits, and proved a definite relationship between them, but did not study the reason for these differences or perform any source diagnostics analysis. In this paper, we continue the study of Parts 1 and 2 to get a deeper understanding of the reason for the differences in PAA installation effects at both approach and take-off power conditions.

\section{Models, Experimental Setup, and Data Processing}

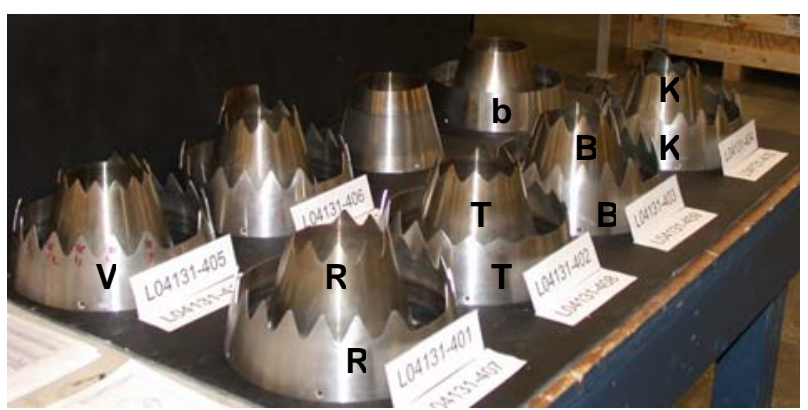

Figure 2. Different types and combinations of conventional chevrons (R), azimuthally varying chevrons ( $T, B, K, V)$, and baseline (b) for fan and core nozzles. (Nozzles not labeled are not used in this paper.)

The description of the various azimuthally varying chevron (AVC) nozzles has been given in Parts 1 and 2 , and will not be repeated here. In brief, for both fan and core nozzles we have the baseline simple splitter round nozzles without chevrons (b), reference state-ofthe-art chevrons which are azimuthally uniform (R), top-enhanced mixing chevrons with less mixing at the bottom $(\mathrm{T})$, bottom-enhanced mixing chevrons with less mixing at the top (B), and top-and-bottom enhanced mixing chevrons with minimal mixing in the middle $(\mathrm{K})$. For the fan nozzle we also had variableimmersion/constant-chord chevrons with K-type of mixing (V). Figure 2 shows a group photo of all these nozzles and is labeled for convenience. Parts 1 and 2 both have a table of test matrix which lists the nozzle combinations which were actually tested in isolated and installed nozzle configurations, respectively.
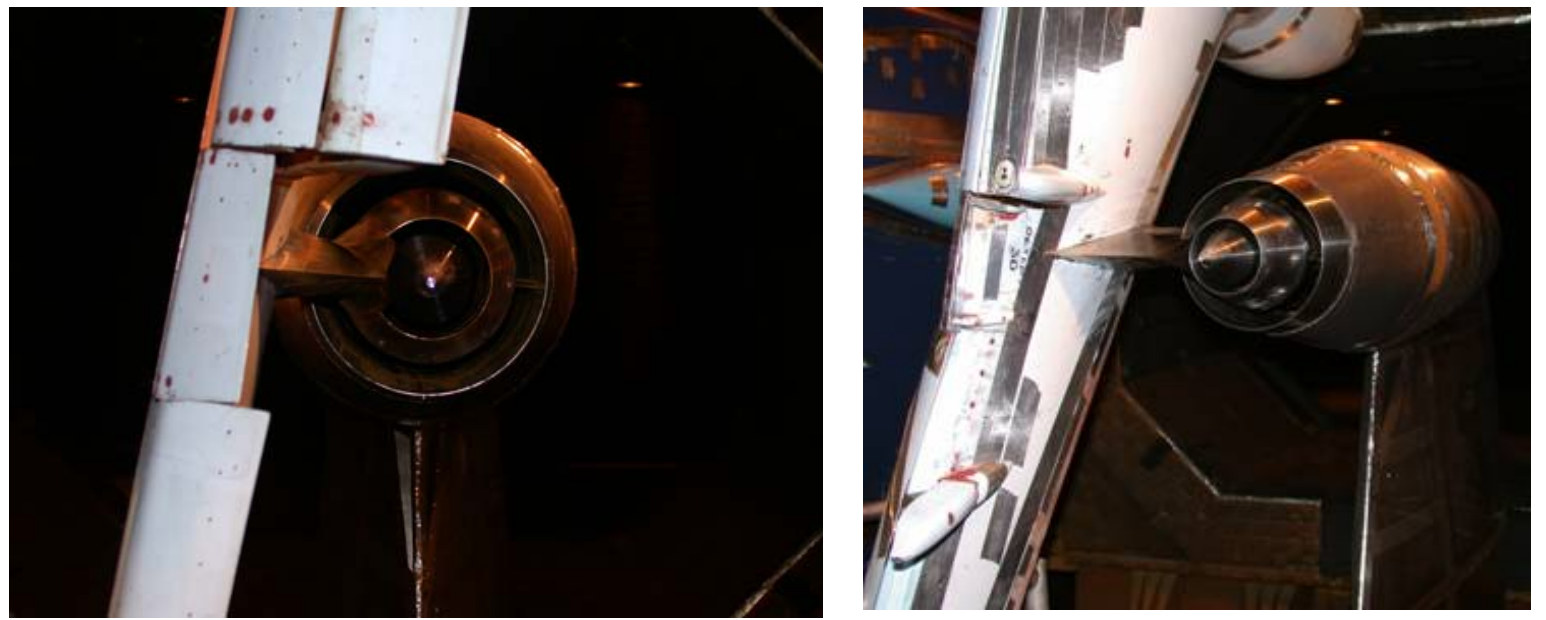

Figure 3. Different views of the scaled baseline nozzle installed under the wing with flaps and flaperon deflected at flap detent angle of $30^{\circ}$, typical at approach (see more photos in the companion paper ${ }^{4}$ ).

The installed nozzle setup, relevant to this paper, with the model-scale nozzle installed under a scaled model wing with fuselage and high-lift devices has been described in Part 2 and will not be repeated here. Briefly, the coaxial nozzle, mounted on NTL3800 jet rig in Boeing's LSAF, is installed under the left wing which is placed approximately vertically in a free-jet wind-tunnel (a dihedral angle of $6^{\circ}$ is included, so it is not exactly vertical but 
at $6^{\circ}$ to the vertical). A fuselage is attached to the wing from the top and the whole airplane model is supported from the top by a right-angled support strut which is partially in the wind-tunnel flow (see Fig. 2 in Part 2).

A typical scaled modern wing for under-the-wing twin-engine applications is used with high-lift devices, such as, inboard and outboard flaps, a flaperon approximately centered on the nozzle center axis, and leading edge slats. These high-lift devices can be configured for different power conditions, such as, approach or cutback or full takeoff or cruise, and are referenced by the flap detent angles which is a consistent set of deflection values for all these high-lift devices. In this paper, we will present results for the approach condition, which has flap detent of $30^{\circ}$, and for the take-off power condition with a flap detent of $5^{\circ}$. Figure 3 shows two different aft close-up views of the flap/flaperon combination at approach conditions. Notice how, with this high deflection of $30^{\circ}$-flap detent at approach conditions, the side edges of the two flaps are almost in the exhaust jet flow, and so is the flaperon trailing edge. Compare the deflected flap positions and their immersion in the jet exhaust to those at take-off conditions at flap detent of $5^{\circ}$ (see Fig. 2(d) in Part 2) - the flap immersion at $5^{\circ}$ is far less than that at $30^{\circ}$. However, recall that the nozzle jet speed is far higher at take-off conditions than at approach.

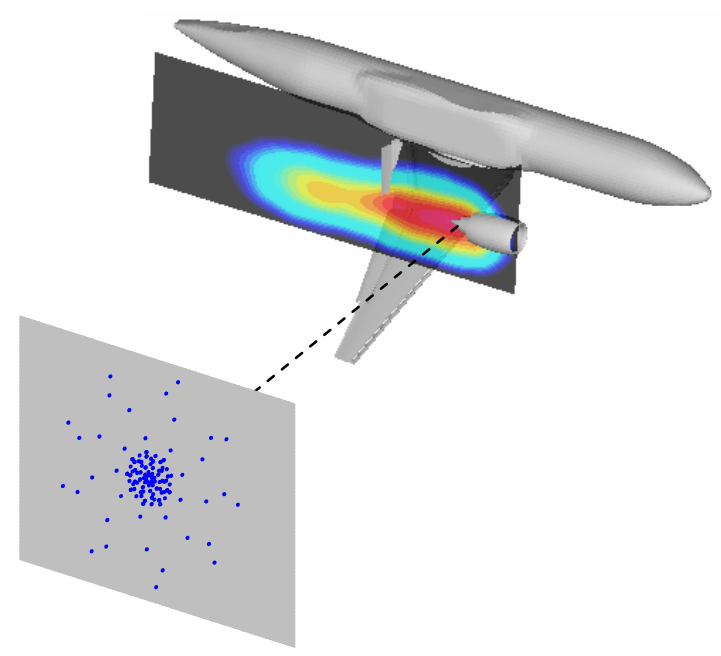

Figure 4. Relative location of the $90^{\circ}$-phased array plane and the grid plane with respect to the installed model (not to scale).

A general description of the LSAF and the two different microphone arrays used in this paper is given in Parts 1 and 2. Briefly, we use a fixed horizontal polar array of microphones placed in a circular arc, centered on the primary exit plane center and spanning an angular region from $60^{\circ}$ to $150^{\circ}$ (measured from the inlet axis). This gives, $\mathrm{R} / \mathrm{D}_{\text {core }}=68.7$ and $\mathrm{R} / \mathrm{D}_{\text {fan }}=32.1$, and is approximately considered to be in the far field. Figure 4 shows a schematic of the phased microphone array in relation to the airplane model and the nozzle, and also an example of a grid plane on the nozzle axis and parallel to the plane of the phased array where source strengths can be calculated. A description of the phased array is given in Part 1. Briefly, it is a spiral array of microphones flush mounted on a vertical plane which can traverse parallel to the wind-tunnel centerline or the nozzle axis at a sideline distance of $\mathrm{b} / \mathrm{D}_{\text {core }}=$ 22.31 outside the wind-tunnel flow. The normal to this plane at its centroid passes through the nozzle centerline axis and is orthogonal to it. The relative location of this array will be denoted by the angle between the line joining this centroid to the core exit plane and the inlet axis. We used it at four angles: $52^{\circ}, 70^{\circ}, 90^{\circ}$ and $125^{\circ}$, and the data from $90^{\circ}$ is used in this paper because it shows the minimum amount of spatial distortion for sources which may be close to the nozzle exit plane or a few diameters downstream. The phased-array microphones themselves are arranged in two logarithmic spiral shapes on a vertical plane: the larger one for analyzing lower frequencies ( $1 \mathrm{kHz}$ to $12 \mathrm{kHz}$ ), and the smaller one for higher frequencies $(10 \mathrm{kHz}$ to $20 \mathrm{kHz})$. We have used data from only the larger spiral array in this paper.

The acoustic data processing from both the far field array and the phased microphone array is described in Parts 1 and 2. Briefly, all data from the far field array is normalized for atmospheric corrections so that acoustic comparisons can be made between any two configurations tested under different test-day conditions. Phased array data was processed using standard beam-forming techniques, mentioned in Part 1, which utilize cross-spectra between two microphones; it was used to find the source strength from any given point in the flow/acoustic field at any given frequency. The source strength presented here is in terms of the source strength measured at the array location (or, effectively, at its centroid), not at the source location. All data presented here is on a vertical grid plane passing through the nozzle axis (see Fig. 4).

\section{Experimental Results and Discussion}

Before we present any data for the installed configurations and jet-flap interaction, it is useful to understand the relationship between the installation effects and the noise benefits. The installation effect, which is the difference between the installed and the isolated configurations for a given nozzle, and its relation to the noise benefits with respect to the baseline nozzle, under isolated or installed configurations, is well-captured in the 4-square noise difference chart, introduced in Part 2, and reproduced as Fig. 5 here. 
Briefly, the four squares in Fig. 5 represent the isolated and the installed noise of the baseline and the modified nozzles, and their corresponding differences are shown on the lines joining these squares as either installation effects or noise benefits. It is clear from this chart in Fig. 5 (and, as explained in detail in Part 2) that if, for a given frequency and angle, the installed nozzle benefit for a modified nozzle is higher than its isolated nozzle benefit, that is, $(c-d)>(a-b)$ then $(c-a)>(d-b)$, which implies that the installation effect of the modified nozzle must be lower than that of the baseline nozzle for the same frequency and angle. Conversely, if the isolated benefit of the modified nozzle is higher than its installed benefit then its installation effect is also higher than that of the baseline. An a priori knowledge of this result will be useful when understanding the installation effects and noise benefits later at different power conditions, approach and take-off, which have different flap detent angles, nozzle jet speeds and wind-tunnel or free jet speeds.

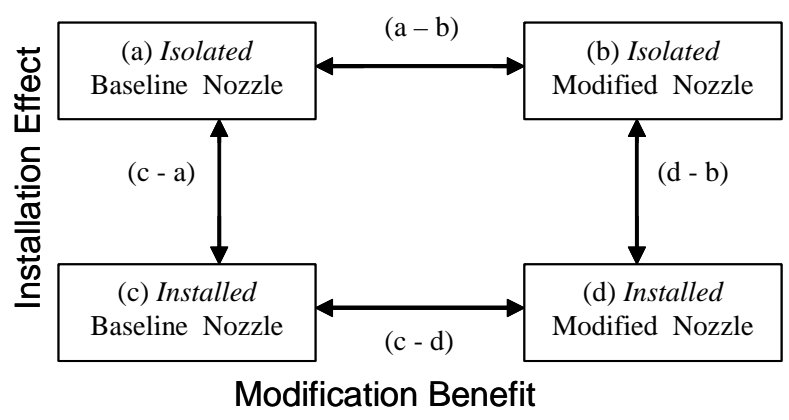

Figure 5. The four-square noise difference chart for installation effects: (c-a) or (d-b), and modified nozzle benefits: (a-b) or (c-d).

In Part 2, we showed the installation effects at takeoff power conditions for some of these nozzles and found that there was some difference in the spectraldirectivity characteristics of the baseline nozzle (bb), the RR nozzle (with conventional R-chevrons on both core and fan nozzles), and the RT nozzle (with conventional R-core chevrons and the T-fan chevrons). Although we linked this to the differences between isolated and installed nozzle benefits, the origin of these differences was not analyzed. Here, we will study the origin or source of these differences at both approach and take-off power conditions and get a deeper understanding of these propulsion airframe aeroacoustic interactions.

\section{A. Approach Conditions}

On the issue of data repeatability, we have shown amply in Parts 1 and 2 earlier that between bands 27 and 47 the data scatter in this test is within $\pm 0.5 \mathrm{db}$ for both static and wind-tunnel on conditions. On the other hand, tunnel noise floor only at $\mathrm{M}_{\mathrm{wt}}=0.30$ was studied there and, found to be adequately below the far field noise of interest at high take-off power conditions when we restrict ourselves to the above frequency bands. However, in this paper our primary interest in jet-flap interaction is at the lower approach power conditions where the nozzle jet speeds are much lower; hence, the jet noise itself will be lower, and the possibility of tunnel noise floor contaminating the far field signal arises even though the tunnel Mach number is also slightly lower, $\mathrm{M}_{\mathrm{wt}}=0.24$.

Our primary interest in this paper, is the "installed" configuration with flaps deflected at approach conditions. The gas conditions at approach used here are: $\mathrm{NPR}_{\mathrm{f}}=1.218, \mathrm{NPR}_{\mathrm{c}}=1.114$ and TTR $=2.096$. Figure 6(a) shows a comparison between the tunnel noise floor at $\mathrm{M}_{\mathrm{wt}}=0.24$ when the nozzle jet is off, the installed noise for the baseline nozzle (bb) with the tunnel on at $\mathrm{M}_{\mathrm{wt}}=0.24$ but no nozzle jet flow, and also the installed noise for bbnozzle with $\mathrm{M}_{\mathrm{wt}}=0.24$ at these approach conditions. It is seen that at very high and very low frequencies there is some tunnel noise contamination at all angles for the installed nozzle, but it changes with the microphone angle. There is a mid-band range and a mid-angle range where the tunnel noise is considerably lower than the far field signal of interest for the installed configuration. Figure 6(b) shows the difference between the first two cases which can be considered as the difference between the airframe noise (inclusive of the noise from the airframe support strut) and tunnel noise. At these approach conditions, it is seen to be much higher than the tunnel noise in the band range of 25 and 35 and, is, hence, usable.

Figure 6(a), importantly, also shows that the installed far field noise (run 275), even at this low-power approach conditions, is well above the tunnel noise floor (run 335) if we restrict ourselves to a certain range of bands (depending on the angle). It, thus, appears usable at most angles, except the shallowest ones, and if we stay away from high frequencies, in general, and the lower frequencies in the aft arc.

\section{Installation Effects}

Let us compare the installation effects at approach conditions for the baseline (bb) nozzle, the RR-nozzle and the RT-nozzle. Figures 6(c), 7(a) and 7(b), respectively, show this installation effect defined as the SPL difference between the installed and the isolated configurations for a given nozzle with wind-tunnel on. We note that: 


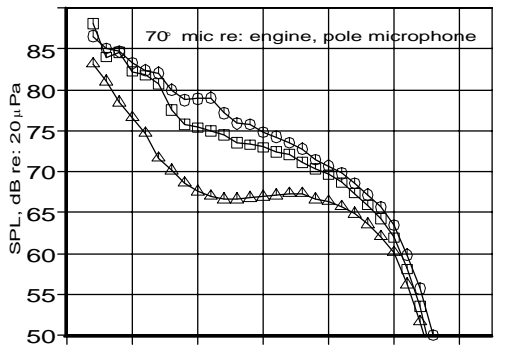

RUN 275 RUN 273 RUN 335
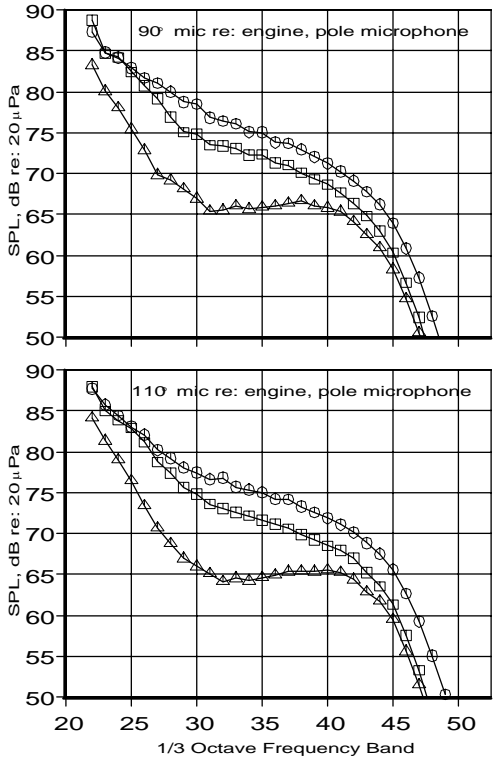
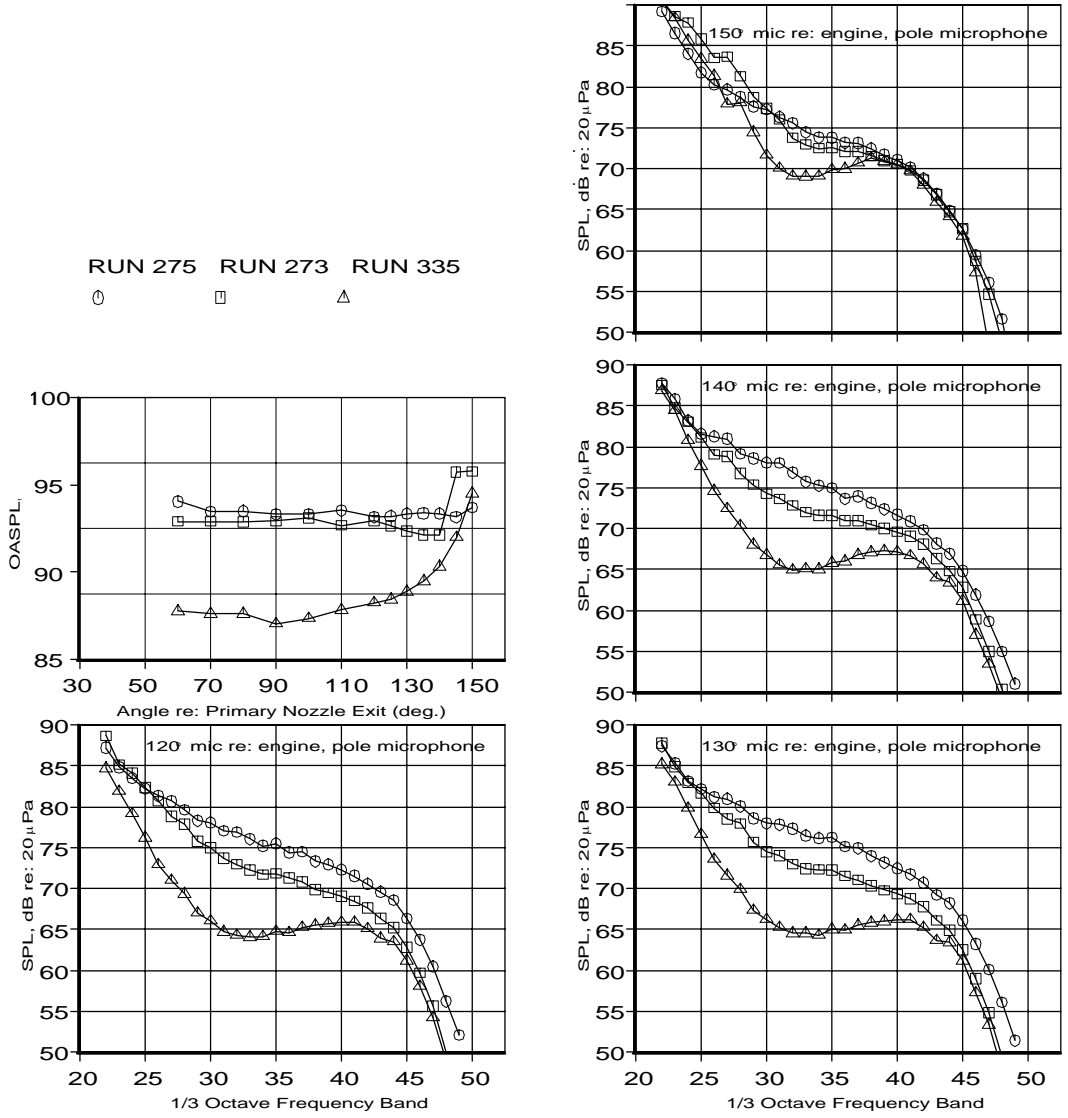

(a) SPL and OASPL comparison

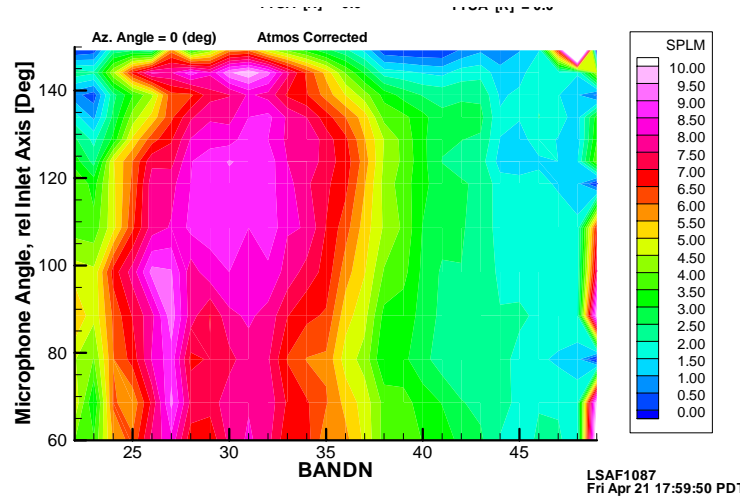

(b) Difference between airframe noise and tunnel noise for bb (run 273 - run 335)

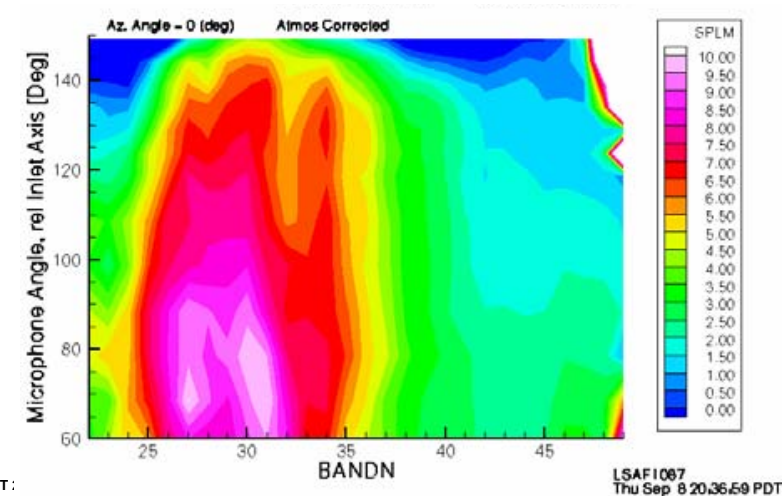

(c) Installation effect for bb (Installed - isolated)

Figure 6. Comparison of tunnel noise floor (Run \# 335), installed baseline (bb) nozzle with baseline airframe at flap detent of $30^{\circ}$ without jet flow (Run\# 273) but tunnel on, and installed bb nozzle at approach conditions (Run \# 275); all runs with $M_{w t}=0.24$.

a) In general, the installation effect for all these nozzles at approach is dominant (above, say, $8 \mathrm{~dB}$ ) for the lower frequencies (below, say, band 33) and the upstream quadrant; but it is also prevalent at a lower magnitude in the downstream quadrant for those low frequencies. 
b) The noise footprint of the installation effect in this spectral-directivity plane (that is, say the area encompassed by a contour of given value) for RR and RT-nozzles is slightly lower than that for the baseline nozzle; RTnozzle appears to have even a slightly smaller footprint than that of RR-nozzle in the upstream quadrant near $70^{\circ}$.

c) From the four-square noise difference chart argument, mentioned earlier, smaller installation effect at a given frequency, $\mathrm{f}$, and angle, $\theta$, must imply better installed noise benefit than in isolated configuration for that (f, $\theta$ ). Thus, at approach conditions, RR and RT nozzles must have higher noise benefits when installed than in isolated configurations; RT must also have a slightly better noise benefit under installed conditions than RR at approach.

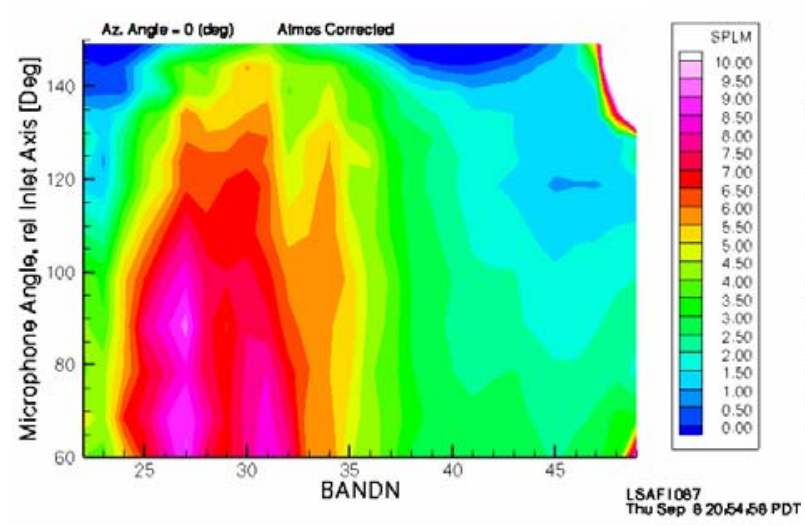

(a) $\mathbf{R R}$

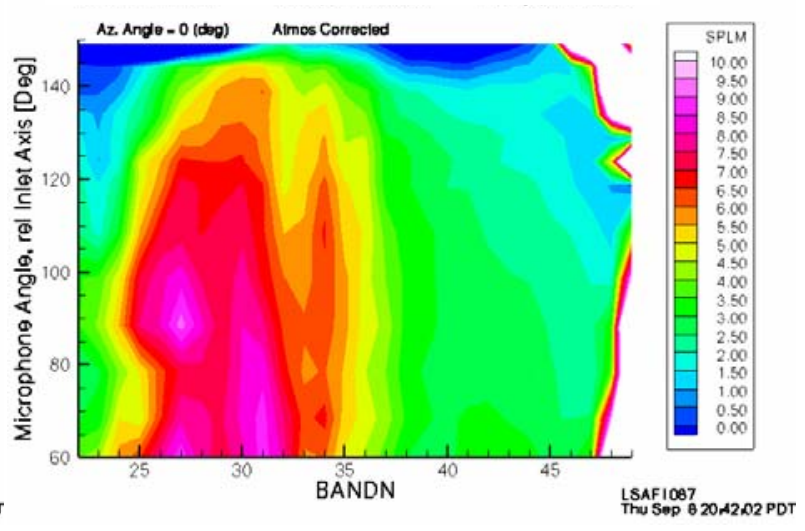

(b) RT

Figure 7. Installation effect for RR and RT nozzle configurations at approach conditions with flaps deflected at $30^{\circ}$ detent and tunnel Mach number, $M_{T}=0.24$.

\section{Source Diagnostics}

The far field SPL data by itself, as in Figs. 6(c) and 7, cannot tell us the reason for these installed differences or where the source of these differences is located. We use the phased array data to resolve this source diagnostics issue. Since the installation effect is the strongest in the upstream quadrant, we will use the $90^{\circ}$-centered phased array data which gives, as mentioned earlier, the smallest axial spatial distortion for sources both close to the nozzle exit plane and a few diameters downstream. Note that since the flow field is downstream of this array centroid location, any line of sight that passes through a noise source and this array-centroid will end up in the upstream quadrant, as explained in Part 1. Rays from sources which are separated axially by only a "small" distance (compared to the sideline distance of the phased array from the nozzle centerline, b) and which pass through this centroid land at only slightly different directivity angles on the far field polar arc of $\mathrm{R} / \mathrm{D}_{\text {core }}=63.7$.

Figure 8(a) shows the $90^{\circ}$-phased array data for the installed baseline nozzle for several frequencies: $1223 \mathrm{~Hz}$ (band 30.9), $2054 \mathrm{~Hz}$ (band 33.1), $6131 \mathrm{~Hz}$ (band 37.9) and $12232 \mathrm{~Hz}$ (band 40.9). We do not consider frequencies lower than this, although there are dominant installation effects there too, because this is the lower limit of the larger phased array data where the data can still be considered good for spatial resolution. For the two lower bands, where the installation effect is stronger than the higher frequencies (see Fig. 6(c)), we see that the most dominant source is near the flap/flaperon trailing edge.** At the higher frequencies another source starts appearing at the nozzle exit plane in addition to the source at the flaperon trailing edge and becomes as strong as the downstream source. Also, as the frequency increases the sound intensity and the footprint of the source near the flaperon trailing edge decreases, while the relative peak SPL values start increasing for the source near the nozzle exit plane.

Does the observation that the source appears to lie near the flaperon trailing edge necessarily mean that it comes from the jet-flap interaction effect or is it possible that it coincides with the usual low-frequency jet noise source near the end of its potential core? To examine that possibility, we need to study the phased array data for the isolated configuration of the same nozzle at the same approach conditions from the same array position. Figure 8(b) shows

\footnotetext{
** Note the different Colorbar Max values for each frequency; the color scale at the bottom gives the value from the Colorbar Max value in any plot. The actual peak SPL value is also denoted for each frequency.
} 

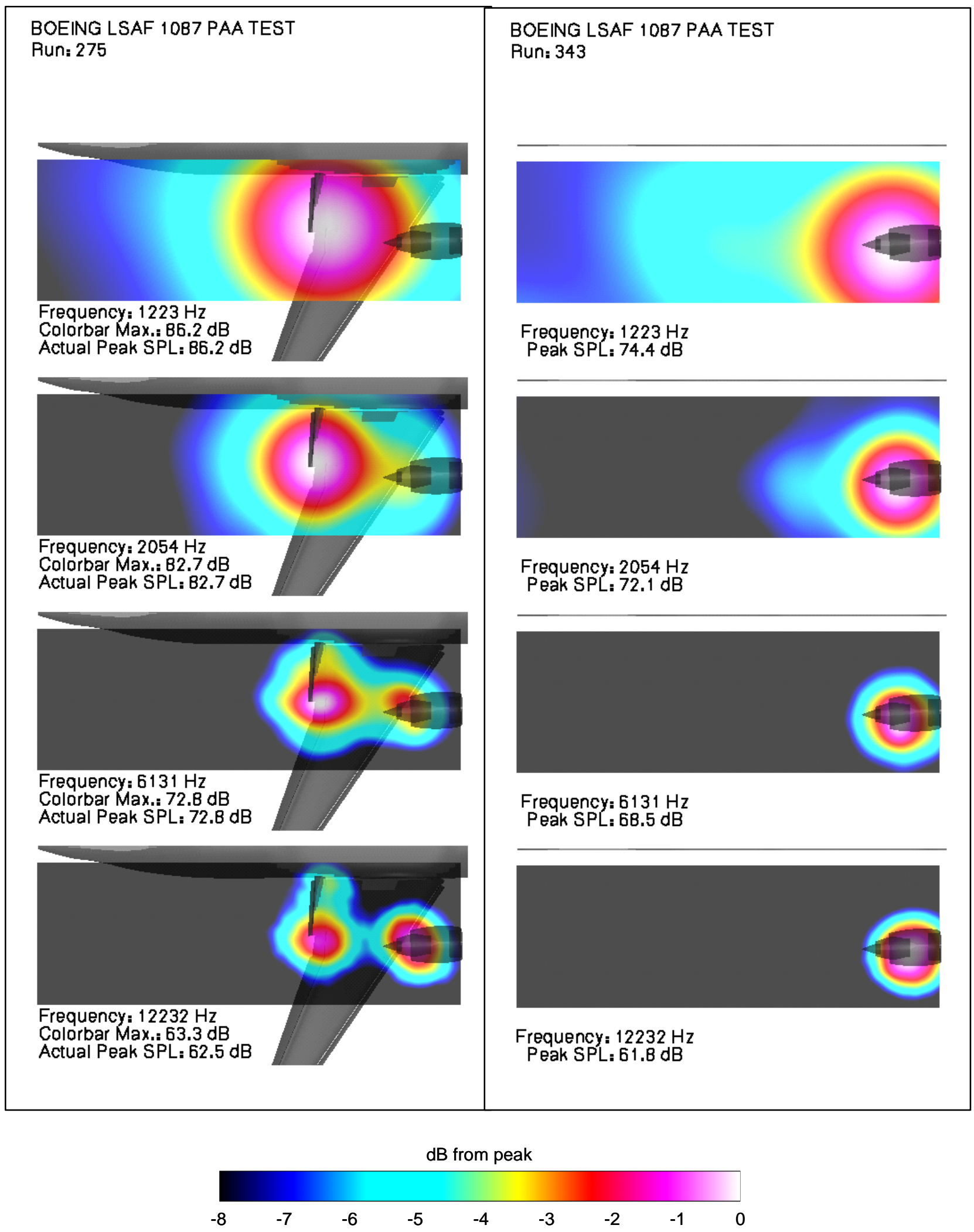

Figure 8. Source diagnostics for jet-flap interaction effect in baseline, bb, nozzle at approach conditions with flap detent at $30^{\circ}$ and $M_{w t}=0.24$ : (a) installed data (Run \# 275), (b) isolated data (Run \# 343). 


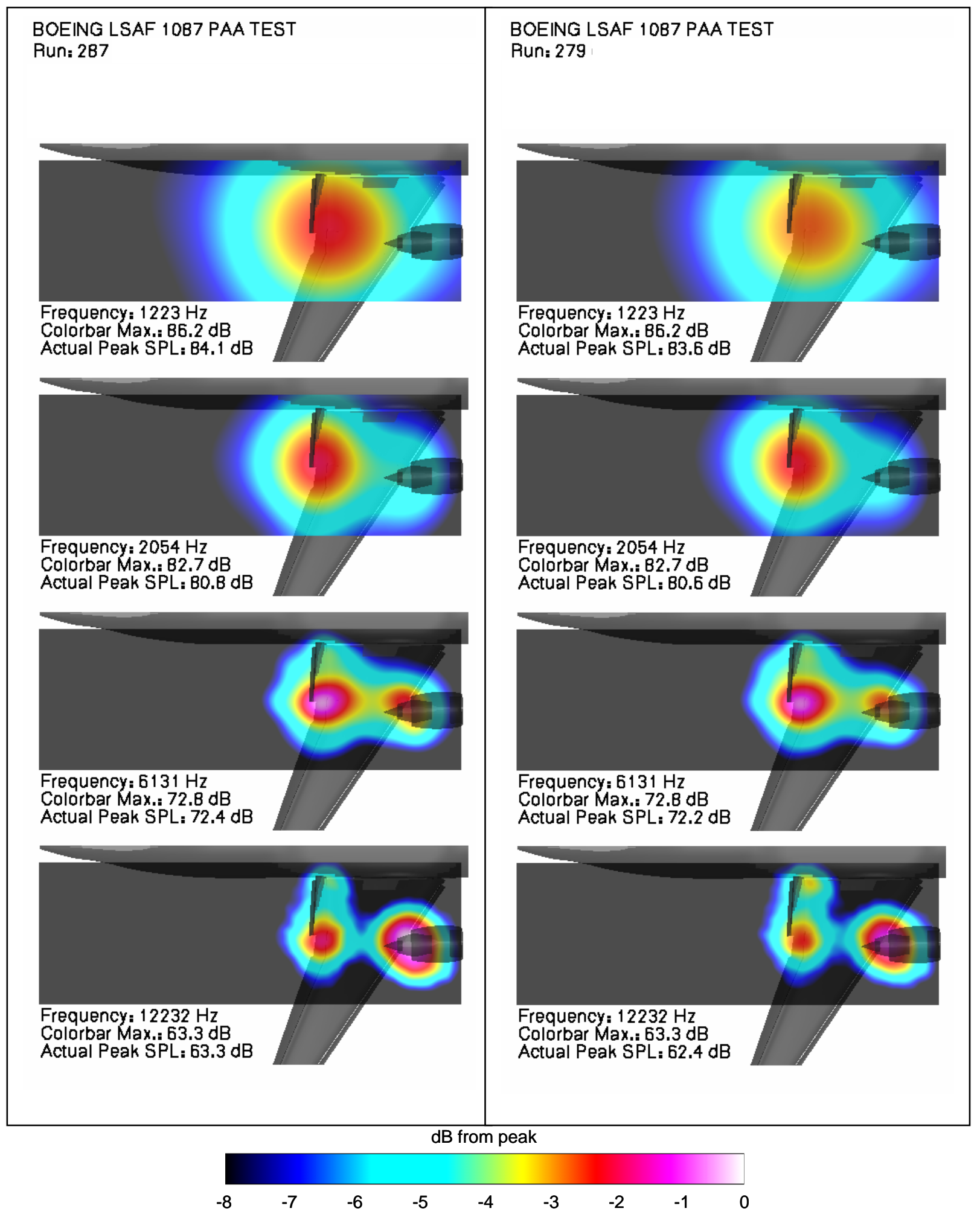

Figure 9. Source diagnostics for jet-flap interaction effect in RR and RT nozzles at approach conditions with flap detent at $30^{\circ}$ and $M_{w t}=0.24$ : (a) RR (Run \# 287) (b) RT (Run \# 279). 
such data for the isolated baseline nozzle: we see that for all frequencies, even the lower ones, the dominant source is located near the nozzle exit plane, not downstream.

As an aside, it is interesting to see why the dominant jet noise source in the isolated case for this approach condition (Fig. 8(b)) is near the nozzle exit plane even at the lower frequencies, and not at some downstream location in the plume, as is usually the case, and as seen in Part 1 (see Fig. 10) for the take-off power condition. It turns out that at the approach condition being studied here, the nozzle jet speeds are much lower than at take-off conditions; so the Strouhal number, inversely proportional to the jet speed, is much higher at approach conditions than at take-off conditions for a given frequency. The classic jet noise sources near the potential core usually correspond to a Strouhal number of 0.3 or so. At higher Strouhal numbers, the dominant jet noise sources, indeed, are known to move to the nozzle exit plane, and are due to the smaller length-scales present in the stronger but thinner shear layers formed with the ambient flow, or due to the fine scale turbulence there which is higher in intensity.

This proves that the source in the installed case near the flaperon trailing edge, hence, must arise from some interaction between the jet, the wind-tunnel flow and the flaperon or flaps. However, the phased-array data cannot spatially resolve whether it arises precisely due to the flaperon trailing-edge interaction or the flap side-edge interaction, but it is in the proximity of that general area. Since the installed noise with the nozzle jet on is only slightly higher than the airframe noise alone, as seen from Fig. 6(a) (comparison of runs 275 and 273), the airframe noise plays a significant role, but we will simply call this source near the flaperon trailing edge as the "jet-flap interaction” source without distinction.

Having settled that this source near the flaperon trailing edge is not due to the jet plume alone but is due to jetflap interaction and airframe noise, let us compare it for RR- and RT-nozzles. If the source strength near the flaperon trailing edge changes due to these chevron nozzles, then the jet-flap interaction must be playing a bigger role than just the pure airframe noise because the chevrons affect the jet plume. Figure 9 shows the source diagnostics results for these installed nozzles at the same approach condition. For convenience, same Colorbar Max scheme for both these nozzles is used at each frequency as for the installed baseline case (Fig. 8(a)), with the actual SPL peak noted for each frequency. Comparison of these peak SPL values immediately reveals that it is, indeed, a JFI effect and is beneficial for both the chevron nozzles, RR and RT: e.g., at $1223 \mathrm{~Hz}$, RR has $2.1 \mathrm{~dB}$ reduction in JFI compared to baseline, whereas, RT has even higher reduction of $2.6 \mathrm{~dB}$; at $2054 \mathrm{~Hz}$, RR has $1.9 \mathrm{~dB}$ reduction, and RT has $2.1 \mathrm{~dB}$ reduction, and so on. Figure 10 shows this reduction in JFI due to RR and RT nozzles as a function of band number. In addition, from Figs. 8(c) and 9, the noise footprint of this source near the flaperon trailing edge is seen to decrease for RR and RT nozzles compared to the baseline, and more so for the RT-nozzle. This is a direct vindication, for the

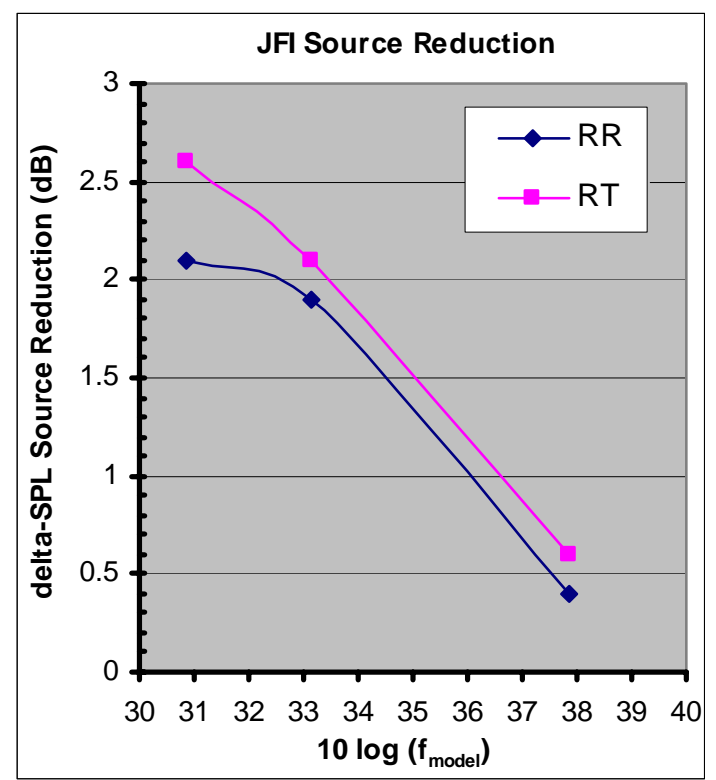

Fig. 10. Jet flap interaction (JFI) noise source reduction by $R R$ and $R T$ nozzles compared to the baseline nozzle at approach power with flap detent of $30^{\circ}$ at $M_{w t}=0.24$. first time, that the T-fan chevrons, in the RT-nozzle, not only reduce the JFI noise source compared to the baseline nozzle, but that they do it better than the conventional chevrons in the RR-nozzle.

Since the rays from these sources at the flaperon trailing edge (located at $\mathrm{L} / \mathrm{D}_{\text {core }}=4.788$ ) which radiate sound to the $90^{\circ}$-array centroid continue their ray paths in the upstream quadrant, they should reduce the far field sound in those upstream angular regions too. A line-of-sight from the flaperon trailing edge center on the source grid plane to the $90^{\circ}$-array centroid is at $81.8^{\circ}$ directivity angle on the far field polar array of microphones. With refraction at the tunnel shear-layer, this gives an angular region upstream of $81.8^{\circ}$, near $75^{\circ}$ or so. Data in Figs. 6(c) and 7, for the baseline, RR and RT-nozzles, corroborate this result, e.g., near $75^{\circ}$ angle and band 31 we see a reduction in the SPL values for RR and RT from the baseline data by $1 \mathrm{~dB}$ or so. For higher frequencies this reduction in JFI source decreases for the chevron nozzles (see Fig. 9 and 8(c)), and so does the far field installation effect (compare Figs. 7 and 6(c)). Thus the far field data for the installed nozzles, in general, appears to corroborate the source diagnostics data.

From the 4-square chart (Fig. 5), it follows that at approach conditions since the installation effect of the chevron nozzles (RR and RT) is less than that of the baseline 
nozzle (bb), the installed benefit of chevron nozzles must be higher than their isolated benefits. It is useful to check that result and for which we need source diagnostics results for the isolated chevron nozzles, similar to the baseline nozzle, Fig. 8(b). From such phased array charts for isolated RR and RT nozzles, we can find these isolated nozzle noise benefits for the same frequencies. These isolated noise source strength benefits, along with the installed noise source benefits, analyzed earlier, are summarized in Table 1 for all the three nozzles, along with their approximate locations.

Table 1. Summary of source diagnostics of most dominant noise source (frequency, approximate location, and amplitude) using $\mathbf{9 0}^{\circ}$-phased array for bb, RR and RT nozzles at approach and take-off power conditions in isolated and installed nozzle configurations.

\begin{tabular}{|c|c|c|c|c|c|c|c|c|c|}
\hline Config. & Frequency & \multicolumn{3}{|c|}{ APPROACH } & \multicolumn{4}{c|}{ TAKE-OFF } \\
\cline { 3 - 10 } & $(\mathbf{H z})$ & Isolated & Benefit & Installed & Benefit & Isolated & Benefit & Installed & Benefit \\
\hline bb & 1223 & 74.4 & & 86.2 & & 89.9 & & 94.1 & \\
& 2054 & 72.1 & & 82.7 & & 88.2 & & 90.0 & \\
& 6131 & 68.5 & & 72.8 & & & & & \\
\hline RR & 1223 & 74.8 & -0.4 & 84.1 & 2.1 & 87.6 & 2.3 & 92.9 & 1.2 \\
& 2054 & 72.3 & -0.2 & 80.8 & 1.9 & 84.8 & 3.4 & 89.2 & 0.8 \\
& 6131 & 68.3 & 0.2 & 72.4 & 0.4 & & & & \\
\hline RT & 1223 & 74.9 & -0.5 & 83.6 & 2.6 & 86.2 & 3.7 & 92.7 & 1.4 \\
& 2054 & 71.5 & 0.6 & 80.6 & 2.1 & 83.6 & 4.6 & 88.6 & 1.4 \\
& 6131 & 67.7 & 0.8 & 72.2 & 0.6 & & & & \\
\hline \multicolumn{7}{|c|}{ at nozzle exit plane } & \multicolumn{7}{|c|}{ near flaperon t.e. } & jet plume downstream & near flaperon t.e. \\
\hline
\end{tabular}

At approach conditions, with low jet speeds, Table 1 shows that the isolated noise sources for these same frequencies are at the nozzle exit plane for the RR and RT chevron nozzles (just like baseline (see Fig. 8(c)), but have very little or negative noise benefit. Although the rays radiating from the nozzle exit plane center to the $90^{\circ}$ array centroid fall in a slightly different angular region on the far field polar arc than the rays from the flaperon trailing edge, both sets of rays still fall in the same general upstream quadrant area due to (i) refraction at the tunnel shear layer, and (ii) fairly small ratio of the distance between the nozzle exit plane and the flaperon trailing edge to the sideline distance of the array.

Thus, we validate that at approach conditions smaller installation effects of RR and RT nozzle, compared to the baseline (ref. Figs. 6(c) and 7), are indeed associated with their larger installation benefits compared to their isolated benefits (ref. Table 1). This is true, as we have seen above, because of low jet speeds at approach condition which favors more JFI reduction by the RR and RT chevron nozzles than reduction of pure isolated jet noise which happens to be at the nozzle exit plane at these high Strouhal numbers. It is interesting to see what happens to this phenomenon at higher jet speeds and lower flap angles, such as, during take-off power conditions - which is analyzed next.

\section{B. Take-off Conditions}

We will study (i) the installation effects at flap detent of $5^{\circ}$ under take-off conditions with tunnel Mach number at 0.30, presented in Part 2, by using source diagnostics, and (ii) fan and core AVC effect on jet-flap interaction noise reduction. The nominal take-off gas conditions used are: $\mathrm{NPR}_{\mathrm{f}}=1.735, \mathrm{NPR}_{\mathrm{c}}=1.622$ and TTR $=2.513$ and the tunnel Mach number is 0.30

\section{Source Diagnostics}

The installation effects of baseline, RR and RT nozzles at take-off power conditions were already discussed in Part 2 (see Fig. 10), and it was found, for example, that the installation effect of RR and RT chevron nozzles was higher than the baseline nozzle. However, since no source diagnostics data was shown in Part 2 no firm conclusions could be drawn about the reason for this, other than to say that, from the 4-square chart (see Fig. 5), the isolated benefits must be higher than the installed benefits. A comparison of the isolated source strengths was already shown in Part 1 (see Table 2) from which the isolated benefits can be concluded, and are repeated in Table 1 here. For example, both RR and RT isolated nozzles have reasonably large source noise benefits (2.3 to $4.6 \mathrm{~dB}$ ) at the lower frequencies shown, coming from source strength reductions in the jet plume far downstream of the exit plane. Now we will study the installed benefits for the same take-off power conditions, and see the reason behind this reversal of trend regarding the installation effect compared to that in the approach conditions. 

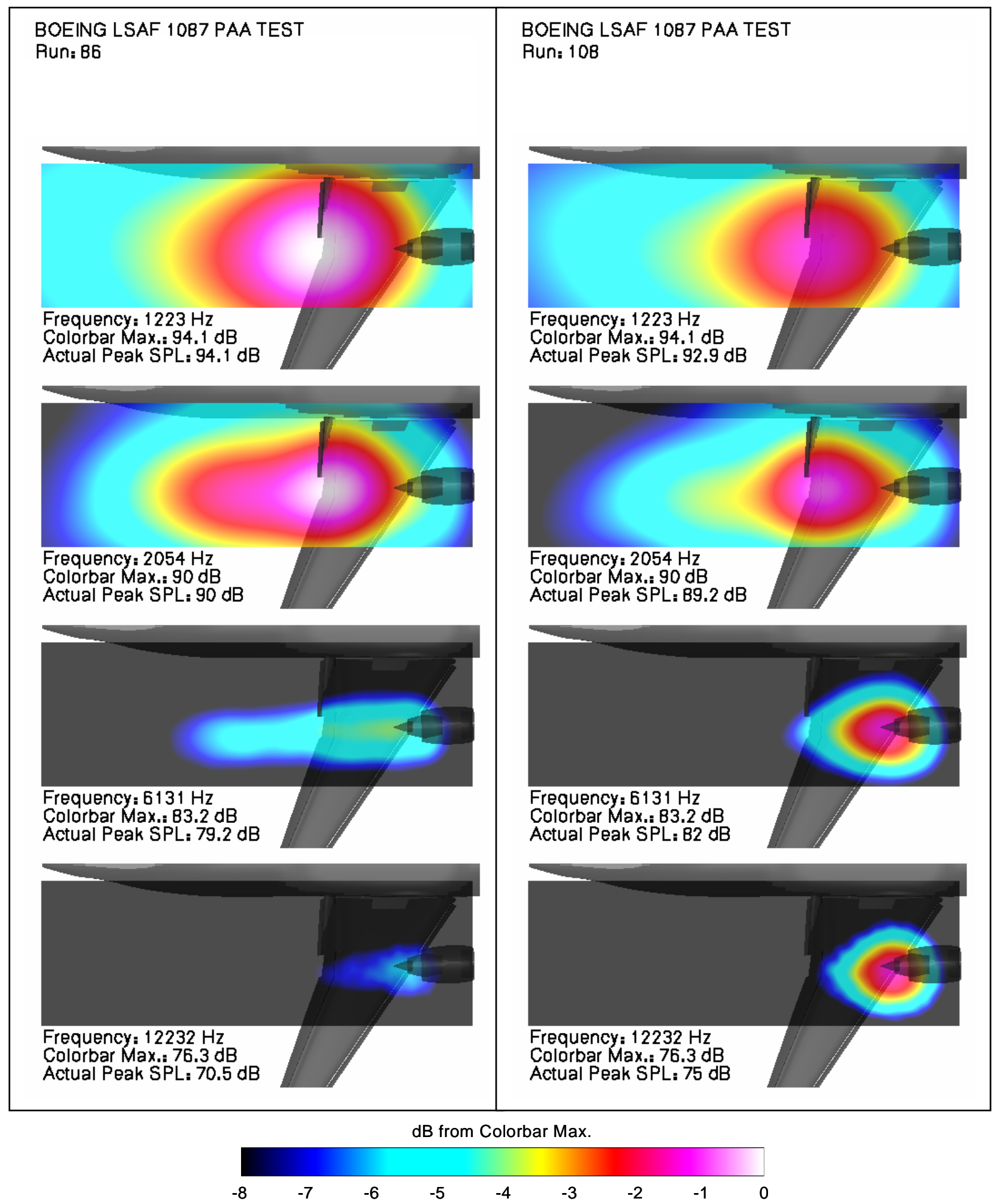

Figure 11 (a-c). Source diagnostics for jet-flap interaction (JFI) effect at take-off sideline power conditions with flap detent at $5^{\circ}$ and $\mathbf{M}_{\mathrm{wt}}=0.30$ : (a) bb-nozzle (Run \# 86) (b) RR-nozzle (Run \# 108) (continued on next page). 


\section{BOEING LSAF 1087 PAA TEST \\ Run: 185}
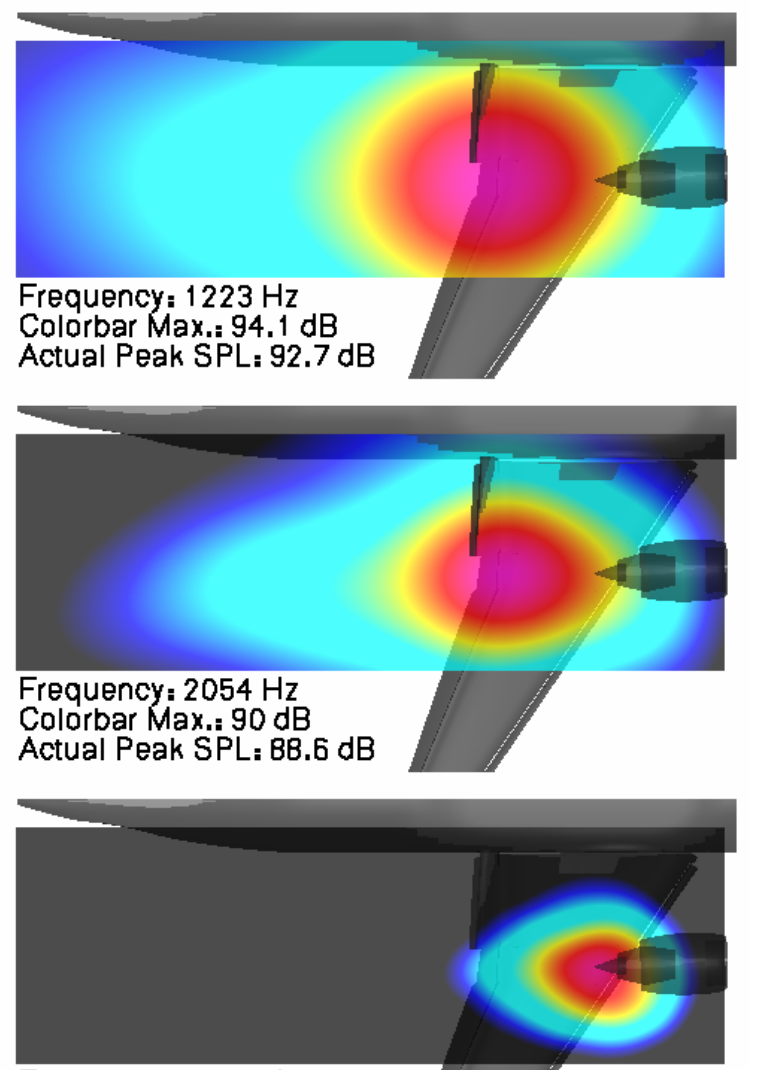

Frequency: $6131 \mathrm{~Hz}$ Colorbar Max.: $83.2 \mathrm{~dB}$ Actual Peak SPL: $B 1.5 \mathrm{~dB}$

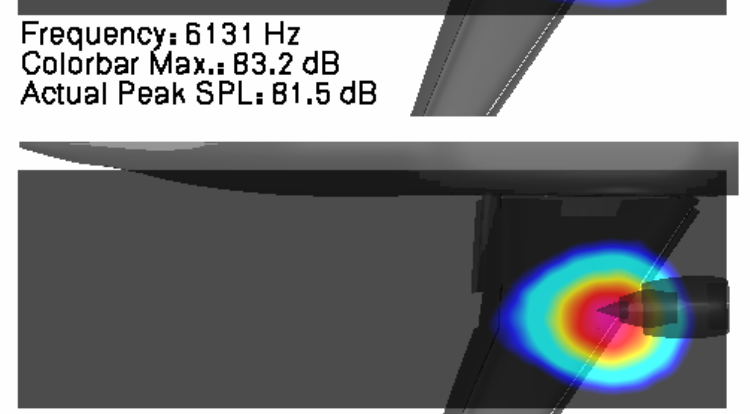

Frequency: $12232 \mathrm{~Hz}$ Colorbar Max.: 76.3 dB Actual Peak SPL: 74.8 dB
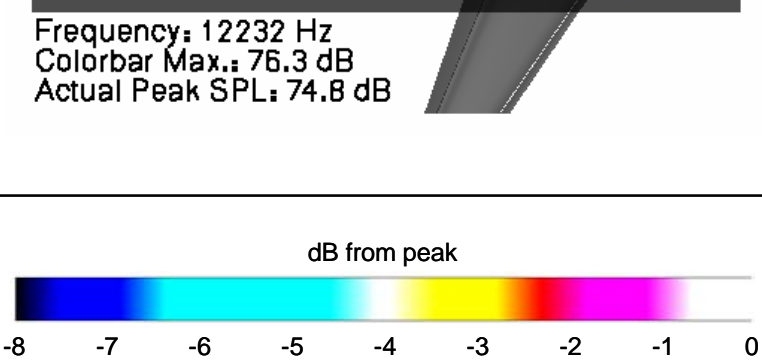

Figure 11 (continued). (c) RT-nozzle (Run \# 185) (for full caption see last page).
Figures 11(a), 11(b) and 11(c) compare the sources, respectively, for the installed bb, RR and RT nozzles under these conditions. For convenience, we have used the same maximum color scale at a given frequency for all the three nozzles:

a) Firstly, it shows that for a given nozzle the source strengths at the flaperon trailing edge are much higher than the dominant sources for the isolated case (Table 1 or Part 1, Figs. 10 and 11). This JFI is what leads to the higher noise under installed condition compared to the isolated one, that is, the installation effect seen in Part 2, Fig. 10. This observation is similar to that at approach conditions.

b) The JFI source strengths and noise footprints for RR and RT nozzles are smaller than that for the baseline nozzle even at take-off power conditions. The installed noise benefits at take-off power are listed in Table 1 in terms of peak SPL reductions, as are the isolated noise benefits.

c) From Table 1 it is seen that the installed noise benefits from JFI reduction for RR and RT nozzles are much smaller ( 0.8 to $1.4 \mathrm{~dB}$ ) than their isolated jet noise benefits in the downstream plume (2.3 to $4.6 \mathrm{~dB}$ ). Although these two sources (one at the flap trailing edge $\left(\mathrm{L} / \mathrm{D}_{\text {core }}=\right.$ 4.788) for the installed case, and the other in the plume $\left(\mathrm{x} / \mathrm{D}_{\text {core }}=9.0\right)$ for the isolated case $)$ are further apart, the rays passing individually through them and the array-centroid are still in the upstream quadrant and one can approximately apply the previous 4-square chart argument. It follows that the installation effect of the chevron nozzles RR and RT must be higher than for the baseline case, as observed in Part 2.

In summary, the reason for the reversal of trends in the PAA installation effects for the chevron nozzles at approach and take-off conditions is that at high jet speeds at take-off, the chevron nozzles are more effective in reducing the jet exhaust noise far downstream in the plume for the isolated nozzle than they are in reducing the jet-flap interaction noise with flaps at a lower angle during the installed configuration. On the other hand, at low jet speeds and high flap angles at approach conditions, they are more efficient in reducing the jet-flap interaction noise than the isolated jet plume noise which is already very weak due to low jet speeds.

2. Fan and Core AVC Effects on Reduction of JetFlap Interaction Noise

Figure 12(a) shows the effect on JFI by holding the core chevron nozzle the same, namely, R (reference conventional chevrons) and changing the fan nozzle systematically from R-chevrons to T (topenhanced mixing) to B (bottom-enhanced mixing) to $\mathrm{K}$ (top and bottom enhanced mixing) to $\mathrm{V}$ (variable 
immersion but constant chord). This figure shows that chevrons, in general, whether azimuthally uniform or not, show JFI noise reduction at the source. However, amongst chevrons there are some differences: RT and RV nozzles appear to give the maximum JFI reduction of about $1.5 \mathrm{~dB}$ at the lowest two frequencies presented; in particular, they are both better than the conventional chevrons RR, and so is the RK nozzle too. It also resolves one of the questions we posed in the beginning of the AVC designs in Part 1, whether it would be top-enhanced mixing (T) or bottom-enhanced mixing (B) that may be beneficial for JFI reduction. Although these are one-point designs, it appears that B-fan chevrons are not as good as the T-fan chevrons for JFI reduction. It is interesting to note that the

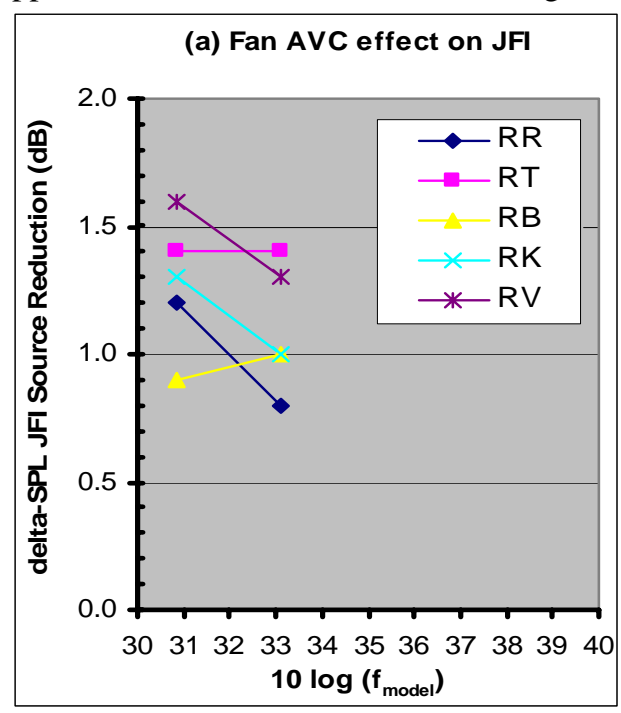

(b) Core AVC effect on JFI

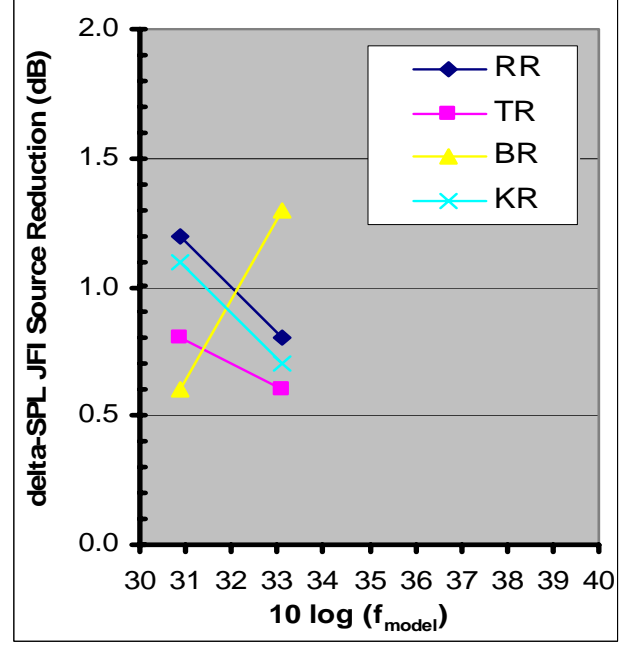

Fig. 12. Fan and core AVC effect on jetflap interaction (JFI) at take-off power with flap detent of $5^{\circ}$ at $M_{w t}=0.30$.

common feature of those fan AVCs that produce better JFI reduction than the conventional R-chevrons $(T, K$ and $V)$ is that all of them have enhanced mixing near the pylon, regardless of how much mixing they have diametrically away from the pylon. In any case, on an overall basis the JFI reduction at take-off power is far less than that at approach conditions.

Figure 12(b) shows the effect of holding the fan nozzle the same, as the reference R-chevrons, and varying the core chevrons from $\mathrm{R}$ to $\mathrm{T}$ to $\mathrm{B}$ to $\mathrm{K}$. This immediately shows that core AVCs are not as good as the reference uniform R-core chevrons in reducing JFI at least at the lowest frequencies. The B-core chevrons in BRnozzle appear to give better JFI reduction at the second lowest frequency than the lowest one. This is similar to the case with B-fan chevrons in the RB nozzle (Fig. 12(a)). This commonality of the Bcore and B-fan chevrons in reducing the JFI noise better than the conventional chevrons at slightly higher frequencies needs further study.

\section{Conclusion}

In this paper, we analyzed the relation between the installation effects and the noise benefits of installed and isolated configurations using an out-of-flow phased array for source diagnostics information. The test matrix included both approach and take-off conditions with different flap settings and tunnel speeds. It was found that azimuthally varying chevrons (AVC), as well as conventional azimuthally uniform chevrons reduce the jetflap interaction noise source at both approach and take-off conditions compared to the baseline nozzle, but some fan-AVCs tested ( $\mathrm{T}, \mathrm{V}$ and $\mathrm{K}$ all of which enhanced mixing near the pylon) reduce it consistently more than the conventional fan chevrons. Furthermore, all core-AVCs tested did consistently worse than the conventional core chevrons, at least at the lowest frequency studied.

One important finding is regarding the reason for the reversal of the installation effect at approach versus take-off. At approach, the installation effect of both types of chevron nozzles (RR and RT) is less than that of the baseline nozzle, whereas, the reverse is true at take-off. This is due to the fact that at low jet speeds and large flap angles, as is the case at approach, these chevron nozzles reduce the jet-flap interaction noise far better than they reduce the jet plume noise (which is already very low) when in the isolated configuration. On the other hand, at high jet speeds and low flap angles, as occurs at take-off, these chevron nozzles reduce the jet plume noise in isolated configurations far better than they reduce the jet-flap interaction noise when in the installed configuration. In the future, these insights will help us reduce this particular component of PAA noise even further.

\section{Acknowledgments}

This work was done in 2004 under NASA Contract NAS1-00086 with Dr. Russ Thomas as the Technical Monitor. Boeing sincerely acknowledges the funding support given by NASA for this pioneering PAA work. We 
would also like to acknowledge the excellent support provided by the whole LSAF group and, in particular, Steve Underbrink and Donn Perkins. Special thanks to Jim Underbrink who designed the phased array.

\section{References}

\footnotetext{
${ }^{1}$ Janardan, B.A., Hoff, G.E., Barter, J.W., Martens, S., Gliebe, P.R., Mengle, V. and Dalton, W.N., “AST Critical Propulsion and Noise Reduction Technologies for Future Commercial Subsonic Engines - Separate-Flow Exhaust System Noise Reduction Concept Evaluation,” NASA/CR-2000-210039, Dec. 2000.

2 Mengle, V.G., “Jet Noise Characteristics of Chevrons in Internally Mixed Nozzles,” AIAA Paper 2005-2934.

${ }^{3}$ Mengle, V.G., Elkoby, R., Brusniak, L. and Thomas, R., "Reducing Propulsion Airframe Aeroacoustic Interactions with Uniquely Tailored Chevrons. 1. Isolated Nozzles,” AIAA Paper No. 2006-2467.

${ }^{4}$ Mengle, V.G., Elkoby, R., Brusniak, L. and Thomas, R. "Reducing Propulsion Airframe Aeroacoustic Interactions with Uniquely Tailored Chevrons. 2. Installed Nozzles,” AIAA Paper No. 2006-2434.

${ }^{5}$ Fink, M.R., "Propulsive Lift Noise,” in Aeroacoustics of Flight Vehicles: Theory and practice. Vol. 1: Noise Sources, edited by Hubbard, NASA RP-1258, Vol. 1, 1991, Ch. 8, pp. 449-481.

${ }^{6}$ Crighton, D.G., “Airframe Noise,” in Aeroacoustics of Flight Vehicles: Theory and practice. Vol. 1: Noise Sources, edited by Hubbard, H.H., NASA RP-1258, Vol. 1, 1991, Ch. 7, pp. 391-447.

${ }^{7}$ Herkes, W., Olsen, R., and Uellenberg, S., "The Quiet Technology Demonstrator Program: Flight Validation of Airplane Noise- Reduction Concepts,” AIAA-2006-2720.
} 